\title{
DAS ESPERTEZAS DE JOÃO GRILO ÀS ARTIMANHAS DE CANCÃO DE FOGO: ENTRE EXPERIÊNCIAS E PROPOSTAS PARA A FORMAÇÃO DE LEITORES NA ESCOLA
}

\section{FROM THE CLEVERNESS OF JOÃO GRILO TO THE TRICKS OF CANCÃO DE FOGO: BETWEEN EXPERIENCES AND PROPOSALS FOR TRAINING READERS AT SCHOOL}

\author{
Anderson Cardoso Silva ${ }^{1}$ \\ Marcelo Medeiros da Silva ${ }^{2}$
}

Resumo: O presente trabalho trata de um conjunto de ações didáticas a partir da leitura de cordéis sobre a temática da esperteza com alunos do $6^{\circ}$ ano do ensino fundamental de uma escola pública no cariri paraibano. Os resultados obtidos foram satisfatórios, uma vez que, através da leitura efetiva do texto literário, pudemos expandir as práticas de leitura na turma em que atuamos, como também fazer com que o gênero cordel circulasse e fosse conhecido, mais amiúde, pelos alunos, assim como levamos os discentes à reflexão crítica acerca do que é ser esperto em nosso país.

Palavras-chave: formação de Leitores; literatura de cordel; ensino de Literatura.

Abstract: This project involves an array of didactic activities carried out with sixth graders from a public elementary school in the Cariri region of Paraíba, Brazil. The project produced satisfactory results: it expanded the students' reading practices, broadened their exposure to the cordel literary genre, and increased the genre's circulation. Finally, the project induced the students to reflect critically on what in means to be "cunning" in their cultural context.

Keywords: reader development; Cordel literature; teaching literature.

\section{Introdução}

As reflexões, ao longo do presente texto, advêm de uma intervenção pedagógica vinculada ao Programa Institucional de Bolsas de Iniciação à Docência (PIBID) da Universidade Estadual da Paraíba (UEPB). O trabalho foi desenvolvido, do final de agosto até à primeira semana de dezembro de 2016, em uma turma de $6^{\circ}$ ano da Escola Municipal de Ensino Fundamental Bento Tenório de Sousa, que fica localizada no assentamento Santa Catarina, no município de Monteiro/PB.

\footnotetext{
${ }^{1}$ Universidade Federal da Paraíba. E-mail: andersomrany031@gmail.com

2 Doutor em Letras pela Universidade Federal da Paraíba, docente do Programa de Pós-Graduação em Formação de Professores e do curso de Letras, área de Literatura, do Centro de Ciências Humanas e Exatas - Campus VI da Universidade Estadual da Paraíba, coordenador de área do Programa Interinstitucional de Bolsas de Iniciação à Docência (PIBID) em Monteiro - PB. E-mail: marcelomedeiros_silva@yahoo.com.br
} 
As ações que constituem o escopo deste trabalho objetivaram despertar o gosto dos alunos pela leitura do texto literário, uma vez que, de acordo com Candido (1995; 2002), acreditamos ser a literatura imprescindível à formação humana porque nos confirma um conjunto de traços que são imprescindíveis para todo e qualquer ser humano, tais como:

[...] o exercício da reflexão, a aquisição do saber, a boa disposição para com o próximo, o afinamento das emoções, a capacidade de penetrar nos problemas da vida, o senso de beleza, a percepção da complexidade do mundo e dos seres, o cultivo do humor. A literatura desenvolve em nós a quota de humanidade na medida em que nos torna mais compreensivos e abertos para a natureza, a sociedade, o semelhante (CANDIDO, 2002, p. 249).

Além disso, nesse processo de formação do gosto literário do nosso aluno, moveu-nos o desejo de formar "um leitor para quem o texto é objeto de intenso desejo, para quem a leitura é parte indissociável do jeito de ser e viver" (RANGEL, 2003, apud SILVA, 2006, p.40). Por isso, o texto literário configurou-se para nós, ao longo de toda a nossa intervenção, em elemento indispensável não só para o ensino/aprendizagem da leitura, mas evidentemente para a iniciação à formação do gosto literário. Para tanto, procuramos realizar atividades que se aproximassem o máximo possível da realidade dos alunos da escola e que, consoante lição de Girotto e Souza (2010), mantivessem uma relação direta com os textos que, em sala de aula, circularam.

Antes de apresentarmos o relato de nossa experiência de leitura literária a partir dos cordéis "A vida de Cancão de Fogo e o seu testamento", de Leandro Gomes de Barros, e "As proezas de João Grilo Neto", de Antônio Lucena, e antes de refletirmos sobre as atividades que foram realizadas com eles, ressaltemos que nossa intervenção pedagógica foi perpassada por inúmeros eventos que, de certo modo, determinaram os rumos que demos às nossas ações na referida escola.

Primeiro, como a experiência integrava um conjunto de ações de um programa do governo federal, a incerteza acerca da permanência ou do encerramento do PIBID gerou certa instabilidade em nós que, dentre as preocupações com as atividades de sala de aula, tivemos de participar das mobilizações em prol da continuidade do programa em um movimento nacional que ficou conhecido como FICA PIBID ${ }^{3}$. Segundo, a professora supervisora e, portanto, regente das aulas na turma em que atuamos só pôde disponibilizar duas aulas semanais da carga

\footnotetext{
${ }^{3} \mathrm{O}$ movimento \#FicaPIBID surgiu em 2016 e foi uma reação contra os cortes impostos ao programa pelo governo federal em uma política de restrição orçamentária que, desde 2014, tem posto em risco a existência do PIBID. [Fonte: http://www.todospelaeducacao.org.br/].
} 
total de horas da disciplina de Língua Portuguesa. Terceiro, a escola onde realizamos a experiência apresenta inúmeros problemas infraestruturais de maneira que, a depender das adversidades climáticas, algumas aulas precisaram ser suspensas.

Essa conjuntura nacional e local contribuiu para que, no conjunto geral, não pudéssemos realizar todas as atividades planejadas na sequência didática previamente elaborada. Contudo, apesar disso, acreditamos ter sido ela válida para nós, professores em formação inicial, e para os alunos com que trabalhamos. Por isso, compartilhamo-la a fim de que possa servir como sugestão de um caminho possível que visa à formação de leitores a partir do contato efetivo dos alunos com o texto literário em sala de aula.

\section{Ensino de leitura e formação de leitores: discutindo o arcabouço teórico-metodológico}

Em reflexão sobre o processo de formação de leitores na educação básica, Ferrarezi Jr e Carvalho (2017) pontuam que o paulatino apagamento da leitura como conteúdo, e não como procedimento, fez com que ela deixasse de ser uma atividade básica e se tornasse acessória. Essa descentralização da leitura nas atividades de ensino na educação básica reflete-se, por exemplo, no sucateamento e no fechamento dos espaços de formação de leitores no interior da própria escola: salas de leitura, biblioteca, dias de leitura, comentários sobre livros lidos, o tempo de ler em sala. Tudo isso deixa de existir ou é minimizado ao extremo a ponto de ser visto como menos importante. O relevante não é mais vivenciar práticas efetivas de leitura, já que, dentro da lógica que enfeixa as práticas realizadas no interior de grande parte das escolas, a leitura passa a ser pretexto para a realização de atividades pontuais (resumos, preenchimento de fichas de leitura, resolução de atividades etc.).

Dentro dessa lógica, o texto deixa de ser objeto de leitura e passa a ser instrumento para a testagem de determinados conteúdos. Do texto passa-se à primazia de fragmentos de texto que são utilizados para a exemplificação, geralmente, de taxionomias gramaticais. Logo, ler como experiência formativa deixou de ser importante e para isso não há mais tempo na escola, uma vez que o importante é ler para realizar alguma tarefa, isto é, para mostrar serviço. A ausência de tempo para ler, possivelmente, está na raiz do fracasso da leitura na escola que, da formação de leitores, passou a priorizar a formação de "bocas e mentes silenciosas" (FERRAREZI Jr.; CARVALHO, 2017). Entretanto, como advogamos, a leitura tem de ser uma prática de formação e não de adestramento. Ler vai além da proficiência exigida para a realização de determinados testes ou instrumentos oficiais de avaliação: 


\begin{abstract}
A escola brasileira perdeu de vez o seu rumo quando esqueceu que educava as crianças e passou a dar mais importância à nota do IDEB do que aos seres humanos sob seus cuidados. Nesse momento, a escola brasileira, tangida por políticas governamentais silenciosas e criadoras de massas ignóbeis facilmente manipuláveis, abriu mão da leitura consistente e civilizadora em favor de uma leitura fragmentada, meramente informativa e sempre aplicada como pretexto para alguma atividade escolástica inútil, como encontrar monossílabos tônicos ou palavras polissílabas (FERRAREZI JR; CARVALHO, 2017, p.20-21).
\end{abstract}

Ante o espanto quando dados emitidos por essas mesmas avaliações externas, a exemplo do $\mathrm{SAEB}^{4}$, apontam que há necessidade de melhorarmos a qualidade do ensino ofertado às nossas crianças e adolescentes, não há que reinventar a roda. Em se tratando do ensino de língua portuguesa, o texto ainda deve ser a unidade básica, como já postulara Geraldi (1997), mas “o texto que nos ensina sobre o mundo, sobre a vida, sobre os sonhos, sobre nossa língua" (FERRAREZI JR; CARVALHO, 2017, p.14). Texto não é exercício de cobrança, mas de diálogo, de encontro, de vivência, troca de experiências.

No caso da formação de leitores, sabemos que ler não se restringe a decodificar. Ler passa pela decodificação, mas a transcende. Ler deve levar o aluno a se comprometer pela e com a linguagem e, consequentemente, aprender outra forma de sentir o mundo e não apenas perceber-se estando no mundo. Lemos não apenas porque precisamos realizar certas atividades. Lemos porque sentimos a necessidade de entrar em contato com bens simbólicos, porque sentimos fome de fabulação, porque precisamos preencher as nossas necessidades de fantasia e de desejo, como já o disse Antonio Candido (1995). Ler aponta para uma necessidade existencial do próprio homem e, uma vez escolarizado, o exercício da leitura exige paciência e tempo, o que não tem sido possível às escolas dentro do modelo de currículo que elas têm e que, no lugar de servir para formar leitores, tem formado não leitores ou, o que é pior, leitor nenhum, já que muitos alunos saem da escola sem saber ler e os que saem, em muitos dos casos, apresentam uma grande ojeriza à leitura, em especial à de textos literários.

Costumeiramente, como vêm apontando trabalhos realizados em nosso país desde a década de 1980, o ensino de literatura, com pequenas variações entre o ensino fundamental e médio, tem falhado na formação de leitores. As causas para isso são inúmeras, mas, de um modo geral, são frutos de uma perspectiva historicista segundo a qual o texto literário ocupa

\footnotetext{
${ }^{4}$ Sistema de Avaliação da Educação Básica (SAEB). De acordo com o portal do Instituto Nacional de Estudos e Pesquisas Educacionais Anísio Teixeira (INEP), o SAEB é composto por um conjunto de avaliações externas em larga escala que permitem ao Inep realizar um diagnóstico da educação básica brasileira e de alguns fatores que possam interferir no desempenho do estudante, fornecendo um indicativo sobre a qualidade do ensino ofertado.
} 
um lugar secundário, visto que o importante é deter-se na vida e obra dos autores (quase não se estudam autoras), na identificação de características dos estilos de época, na classificação de figuras de linguagem ou no reconhecimento de uma taxionomia gramatical. Em todos esses casos, a literatura é tomada como um apêndice da disciplina de Língua Portuguesa e o seu ensino é marcado por protocolos e convenções que circulam na escola e que distanciam leitor e texto.

Como pontua Alves (2014), os trabalhos que tomam, em nosso país, a relação entre literatura e ensino como escopo vêm se centrado no diagnóstico da "falência do ensino de literatura como contribuição para a formação de leitores", nos problemas inerentes aos materiais pedagógicos, especialmente os livros didáticos "que servem de suporte para o ensino" ou na realização de intervenções que almejam "experimentar práticas mais dialógicas com o texto literário, o contexto escolar" ou visam diagnosticar "as leituras dos jovens - que acontecem à revelia dos conteúdos escolares" (ALVES, 2014, p. 10). Todavia, apesar da existência de muitos trabalhos que compartilham experiências exitosas na formação de leitores de literatura a partir da educação básica, percebemos que as pesquisas sobre o ensino de literatura em nosso país, em sua maioria, ainda se configuram como uma espécie de "um samba de uma nota só", pois permanecem reiterando o fracasso da escolarização da literatura. Por isso, concordamos com Silva (2017) quando, sobre tal cenário, faz a seguinte afirmação:

\footnotetext{
Embora saibamos que existem entraves para que essa escolarização aconteça de maneira eficaz, ainda assim, acreditamos que precisamos superar o discurso da queixa e passar a compartilhar práticas exitosas que, mesmo diante das mais diversas adversidades, têm provocado reflexos na educação básica e formado leitores de literatura, sujeitos para quem o texto literário não é simples pretexto, mas, sim, alimento, espécie de pão que nutre não mais as necessidades do corpo físico, mas, sim, do espírito (SILVA, 2017, p. 114).
}

Na contramão das práticas tradicionais que ainda perpassam o ensino de literatura e dos discursos que reiteram o fracasso da escolarização literária, advogamos que é "função da escola levar os alunos a obterem experiências significativas e a superarem obstáculos na compreensão [sobretudo, do texto literário]" (MARTINS, 2015, p. 55). Por isso, o objetivo das ações desenvolvidas por nós foi criar condições didático-metodológicas para que os alunos com os quais trabalhamos pudessem ter experiências significativas com os cordéis "A vida de Cancão de Fogo e o seu testamento", de Leandro Gomes de Barros, e "As proezas de João Grilo Neto", de Antônio Lucena. Ambos tratam da vida de dois camaradas, ou, como no universo popular 
são conhecidos, de dois Amarelinhos, que se safaram de inúmeras situações embaraçosas, valendo-se, para tanto, da astúcia como única arma de luta e resistência.

Por isso, valemo-nos, antes da leitura efetiva do texto literário, de atividades motivacionais que preparassem, previamente, os alunos para o contato com a temática a partir de atividades para cuja solução os alunos precisavam, justamente, de se valer da esperteza. As motivações que levamos para a sala de aula se deram por meio de dinâmicas ou por intermédio de questionamentos, uma vez que, na esteira de Geraldi (1997, p. 168 [grifos nossos]), “a primeira pergunta a fazer [ao texto] é para que se lê o que se lê?’. Esse tipo de questionamento, como vamos ver na subseção de análise, fez com que pudéssemos refletir não somente sobre a narrativa, mas também sobre o comportamento psicológico e a influência cultural e política dos personagens protagonistas dos cordéis.

Tanto nesses momentos iniciais de descontração, já que as atividades de motivação podem e devem ser momentos lúdicos por meio dos quais se pode dar a aprendizagem, quanto nas ocasiões em que o objeto de reflexão era o texto literário, primamos por um trabalho devidamente planejado, já que, para nós, o exercício docente não pode ocorrer de qualquer maneira, nem tampouco ser pautada à base de "improvisos pedagógicos". Em se tratando do trabalho com o texto literário, seguimos as orientações de Albuquerque \& Leal (2010), para quem há uma necessidade de planejar e relacionar todas as atividades propostas, uma vez que:

[...] a inserção da literatura em sala de aula não pode ser algo ocasional, acidental e nem pode fazer parte de um preenchimento de tempo sem intencionalidade. $\mathrm{O}$ professor precisa realizar atividades constantes, planejadas, em que os estudantes tenham acesso ao texto literário, mas possam também refletir coletivamente sobre tais textos. (ALBUQUERQUE; LEAL, 2010, p. 101).

Assim, todas as atividades que a seguir serão descritas e analisadas não surgiram do nada. Foram pensadas e repensadas antes de serem executadas em sala de aula. Foram, sobretudo, atividades que, a partir de motivações didáticas específicas, levaram sempre em consideração o contexto sociocultural dos alunos.

\section{A esperteza na escola: uma proposta de (e para a) sala de aula}

As atividades que, nessa subseção, serão apresentadas têm como base os dois cordéis a que fizemos referência em parágrafos anteriores e se pautaram em torno da temática da esperteza, à qual chegamos depois da aplicação de um questionário que objetivou sondar as 
preferências de leitura dos alunos, isto é, os gêneros, as temáticas de que mais gostavam. Procedemos dessa forma porque acreditamos que uma das incoerências em muitas ações na formação de leitores, a partir da escola, é não fazerem uma consulta prévia a esses leitores e, assim, traçar o seu perfil:

Muitas vezes, descobrimos o universo de interesse através das "agendas" de alunos e alunas. O método mais comum era perguntarmos de forma direta (ouvindo e anotando, através de pequenas fichas; organizando entrevistas elaboradas pelos próprios alunos, etc.). Outra é descobrindo os filmes que mais apreciam, os programas de rádio e televisão a que assistem, as novelas de que mais gostaram... (PINHEIRO, 2002, p. 25).

No questionário que aplicamos, havia perguntas, como: Você costuma ler com frequência?; Quais temas, na sua concepção, são mais atrativos?; Quais são suas práticas diárias de escrita?; Que tipos de livro você gosta?. A partir das respostas a essas e a outras perguntas que o questionário continha, foi possível traçar um perfil dos leitores que havia na turma do $6^{\circ}$ ano da escola Bento Tenório de Souza no ano letivo de 2016. Diante do exposto, é válido apontar que as práticas de leitura e escrita dos alunos eram poucas, porém não eram inexistentes, uma vez que se restringiam às poucas leituras da escola ou às leituras diárias das redes sociais, a exemplo do Facebook. O perfil dos alunos, a que nos referimos anteriormente, era configurado pela aversão à leitura, seja porque acreditavam que o ato de ler era enfadonho, seja porque não tiveram, em suas vidas, incentivos para práticas efetivas de leitura. Contudo, a partir da aplicação de um questionário para a sondagem do perfil leitor da turma em que atuamos, detectamos alguns textos e temáticas que chamavam a atenção dos alunos. Por isso, escolhemos o gênero cordel e a temática da esperteza, o que nos levou à escolha dos cordéis "A vida de Cancão de Fogo e o seu testamento", de Leandro Gomes de Barros, e "As proezas de João Grilo Neto", de Antônio Lucena, que motivaram as ações que, agora, passamos a descrever.

Como primeira atividade, realizamos a Dinâmica do UNO. Nesse caso, utilizamos o tradicional jogo $U N O^{5}$. Primeiramente, apresentamos o jogo para a turma e expusemos as suas principais regras. Em seguida, simulamos uma partida do jogo entre nós, professor, e alunos, a fim de verificarmos se a turma havia compreendido como o jogo funcionava. O objetivo ainda não era ver quem se sagraria vencedor. Logo após, realizamos a etapa mais importante: mediar

\footnotetext{
${ }^{5}$ É um jogo de cartas mundialmente conhecido. O objetivo dele é fazer com que o adversário fique com o máximo de cartas possíveis na mão. Na brincadeira, cada jogador recebe 7 cartas. O restante do baralho é deixado na mesa com a face virada para baixo e então vira-se a primeira carta do monte. Esta carta que fica em cima da mesa serve como base para que o jogo comece.
} 
um momento de reflexão para que os alunos pudessem expor quais estratégias foram usadas para desenvolver o jogo e, consequentemente, vencer os oponentes. Nesse momento, objetivávamos saber se algum deles iria fazer menção à necessidade de, para se sagrar vencedor, o jogador teria de se mostrar esperto:

Figuras 1: Dinâmica do UNO
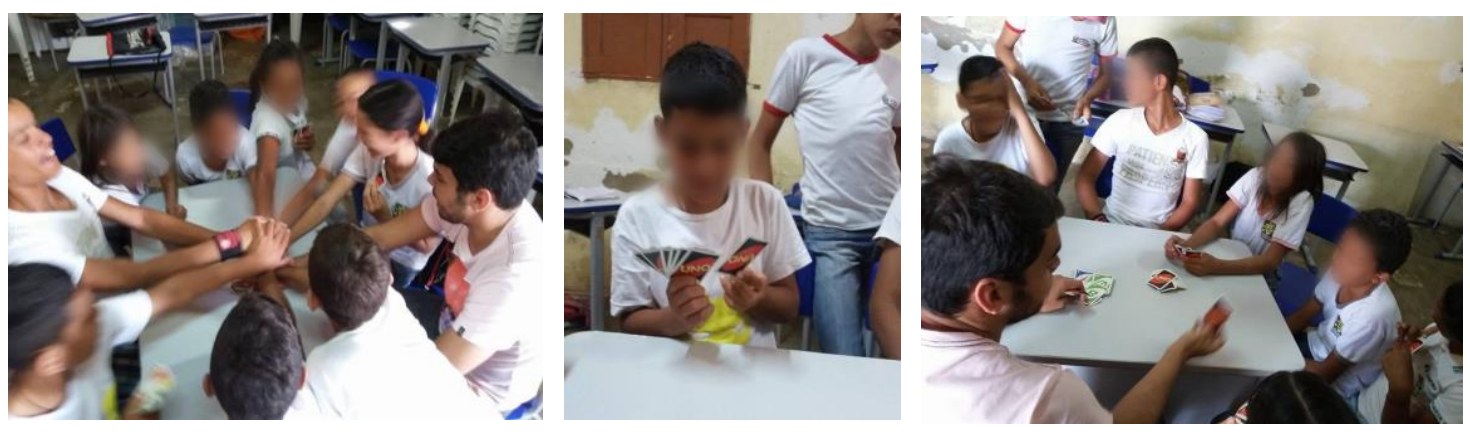

Fonte: Acervo pessoal do pesquisador.

Depois desse momento de motivação, os alunos estavam preparados, então, para recepcionar a leitura do primeiro texto literário: A vida de Cancão de fogo e o seu testamento. O cordel narra a história de um homem que desde criança sabia iludir todos e que, ao longo da sua vida, promoveu inúmeras artimanhas para poder se dar bem, conforme podemos perceber no trecho abaixo:

Leitor, se não se enfadar

Desta minha narração

Leia a vida deste ente:

E preste toda a atenção,

Que foi o quengo mais fino

Desta nossa geração...

Pois ele, desde criança,

Sabia a tudo iludir;

Estradeiro muito velho

Não o pode competir:

O Cancão nunca armou laço

Que alguém pudesse sair.

Cigano, que no Egito

O temiam como a um lobo,

Entre todos os ladrões

Era o professor do roubo,

Chegou aqui no Brasil:

O Cancão fez dele um bobo... 
(BARROS, 2002, p. 1-2)

Antes de iniciarmos a leitura propriamente dita, lançamos a seguinte pergunta para a turma: "Para vocês, o que é um cancão de fogo?". As respostas dos alunos foram várias e disseram respeito não só à figura de um pássaro da região Nordeste, como também à figura de uma pessoa ruim, sem leis e regras, que dá dor de cabeça aos que estão por perto. Além da pergunta, levamos cópias da capa do cordel para que os alunos pudessem realizar inferências não só sobre as imagens presentes nelas como também sobre o título e, consequentemente, sobre o próprio cordel criado por Leandro Gomes de Barros.

Entre o momento de discussão da capa do cordel e de levantamento de hipóteses acerca do que seria um cancão de fogo, foi realizada a Dinâmica da caixa mágica, com o intuito de testar as habilidades dos alunos. A caixa mágica é um brinquedo artesanal produzido na região Nordeste, que consiste em enganar as pessoas que se arriscam a abri-la. Para abrir a caixa, não é necessário nenhum tipo de força bruta, há somente a necessidade de encontrar os pontos de extremidade que tornam possível a abertura do objeto ${ }^{6}$. Logo, os alunos precisavam encontrar as estratégias adequadas para tentar conseguir abrir o objeto.

Figura 2: Dinâmica da caixa mágica

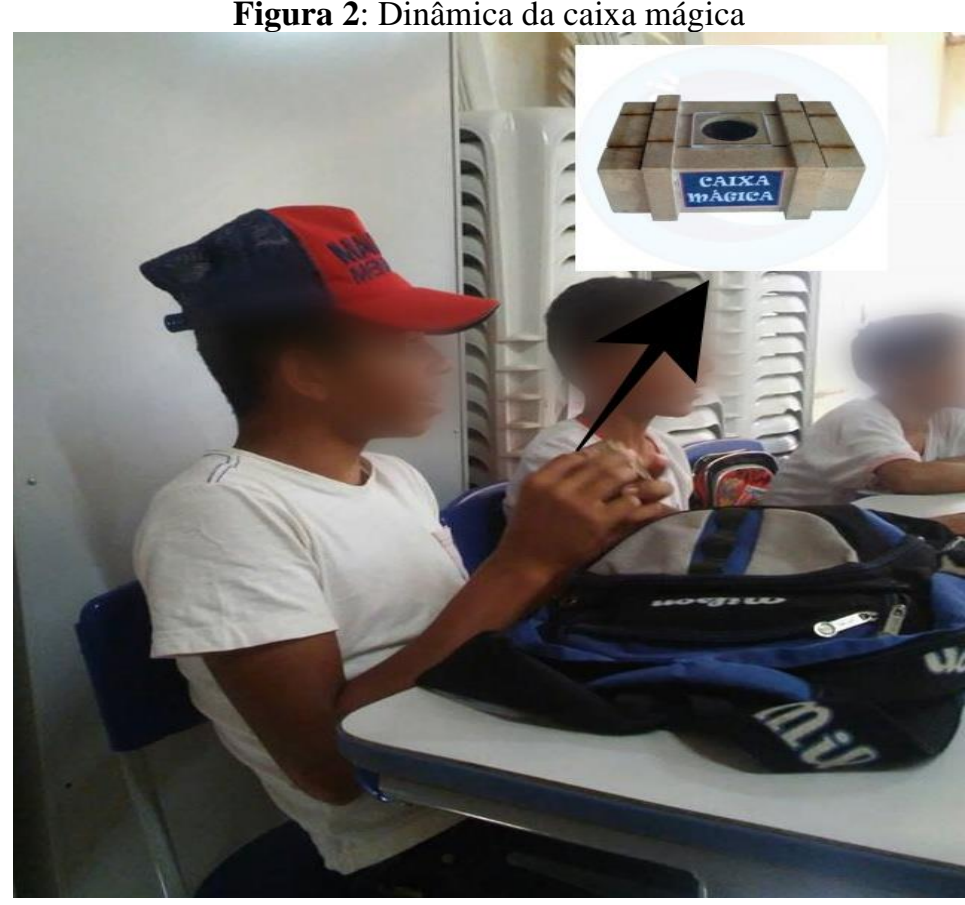

Fonte: Acervo pessoal do pesquisador

6 A título de maiores esclarecimentos, segue um video explicando como abrir a caixa mágica: https://www.youtube.com/watch?v=BAyzF0GNeUQ. 
Depois disso, partimos para a leitura do cordel que não foi entregue na integra à turma. Dividimo-lo em blocos situacionais ou blocos de leitura ${ }^{7}$, a fim de que cada pausa na leitura pudesse instigar na turma a curiosidade para ler os próximos momentos do texto. Para tanto, a cada finalização de um desses blocos, era realizada uma discussão guiada pela seguinte pergunta: “Como vocês agiriam diante da situação se estivessem no lugar do protagonista?". Dessa forma, o cordel foi dividido conforme descrito no quadro abaixo:

Quadro 1: Estratégia de divisão para a leitura do cordel $A$ vida de Cancão de fogo e seu testamento, de Leandro

\begin{tabular}{|c|l|l|}
\hline $\begin{array}{c}\text { Bloco de } \\
\text { leitura }\end{array}$ & \multicolumn{1}{|c|}{ Título } & \multicolumn{1}{|c|}{ Localização no cordel } \\
\hline 1 & Descrição do protagonista & $\begin{array}{l}\text { Página 1 até o final da primeira estrofe da } \\
\text { página } 7 .\end{array}$ \\
\hline 2 & $\begin{array}{l}\text { A importância do protagonista } \\
\text { para o mundo }\end{array}$ & $\begin{array}{l}\text { Segunda estrofe da página 7 até o final da } \\
\text { primeira estrofe da página 12. }\end{array}$ \\
\hline 3 & $\begin{array}{l}\text { As viagens de Cancão mundo } \\
\text { afora }\end{array}$ & $\begin{array}{l}\text { Segunda estrofe da página 12 até o final } \\
\text { da terceira estrofe da página 17. }\end{array}$ \\
\hline 4 & $\begin{array}{l}\text { O reencontro de Cancão com os } \\
\text { seus familiares }\end{array}$ & $\begin{array}{l}\text { Quarta estrofe da página 17 até a segunda } \\
\text { estrofe da página 21. }\end{array}$ \\
\hline 5 & $\begin{array}{l}\text { A entrada do Cancão na } \\
\text { marinha }\end{array}$ & $\begin{array}{l}\text { Terceira estrofe da página 21 até a página } \\
24 .\end{array}$ \\
\hline 6 & $\begin{array}{l}\text { A viagem do Cancão ao Ceará } \\
\text { O desfecho }\end{array}$ & $\begin{array}{l}\text { Página 25 até a terceira estrofe da página } \\
28 .\end{array}$ \\
\hline 7 & 32. \\
\hline
\end{tabular}

Fonte: Elaborado pelo pesquisador.

Como forma de não deixar a leitura monótona e evitar que os alunos viessem a abandonar o texto, criamos, entre o terceiro e quarto bloco, a Dinâmica do caboclo esperto, a

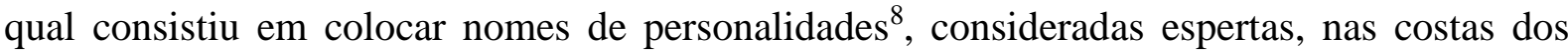

\footnotetext{
${ }^{7}$ Como o personagem Cancão de Fogo passa por inúmeras situações, dividimos todo o cordel, tendo como categoria de divisão as situações vividas pelo protagonista.

${ }^{8} \mathrm{Na}$ lista, havia protagonistas de cordéis, como: Pedro Quengo, João Grilo, Chicó, Vicente (rei dos ladrões), Cancão de Fogo e Pedro Malasartes, bem como personagens politicos, como: Eduardo Cunha, Aécio Neves e Cássio Cunha Lima.
} 
alunos para que, em duplas, eles tentassem adivinhar qual nome estaria colado nas costas do colega:

Figuras 3: Dinâmica do caboclo esperto

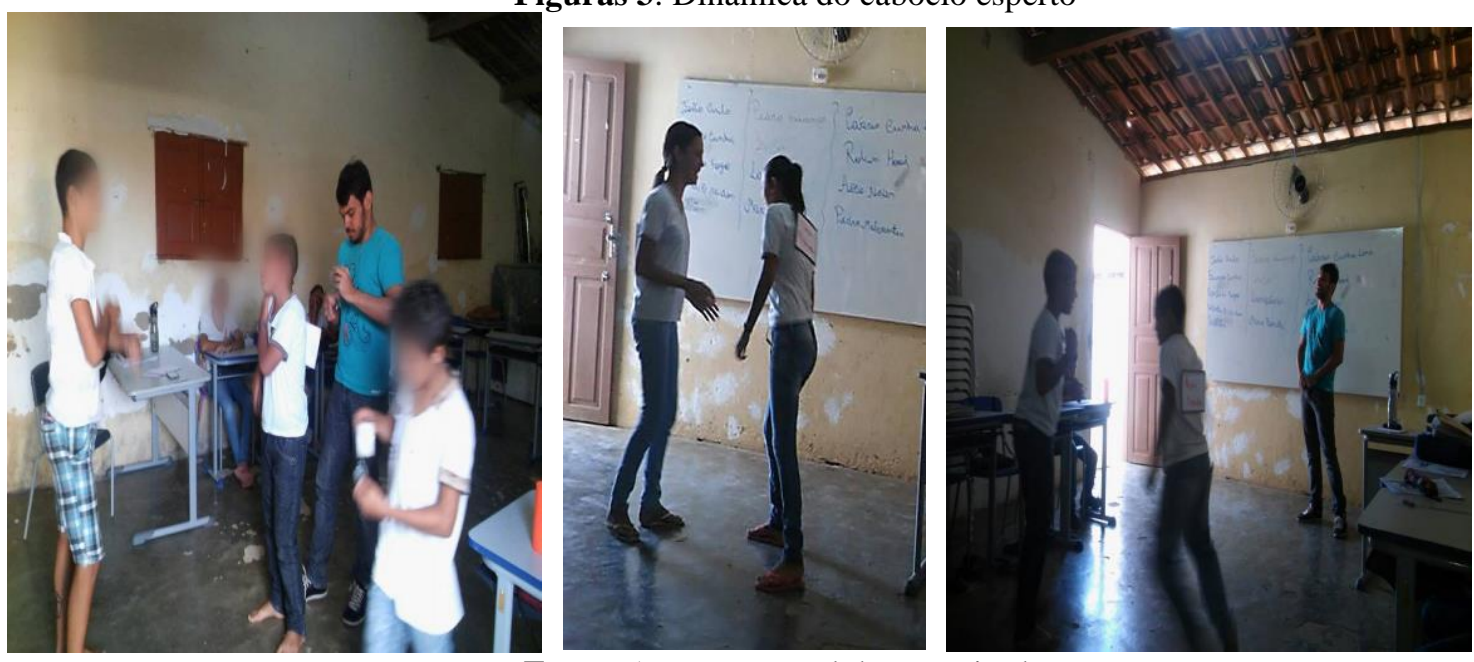

Fonte: Acervo pessoal do pesquisador.

Através desses blocos de leitura e da Dinâmica do caboclo esperto, foi possível não somente sistematizar a leitura, como também discutir melhor sobre o texto que, inclusive, é um pouco extenso. Depois de ler todo o cordel, realizamos mais uma atividade lúdica: a dinâmica da argola. A brincadeira consistiu em retirar a argola amarela, conforme podemos ver na imagem abaixo, do brinquedo:

Figura 4: Dinâmica da argola

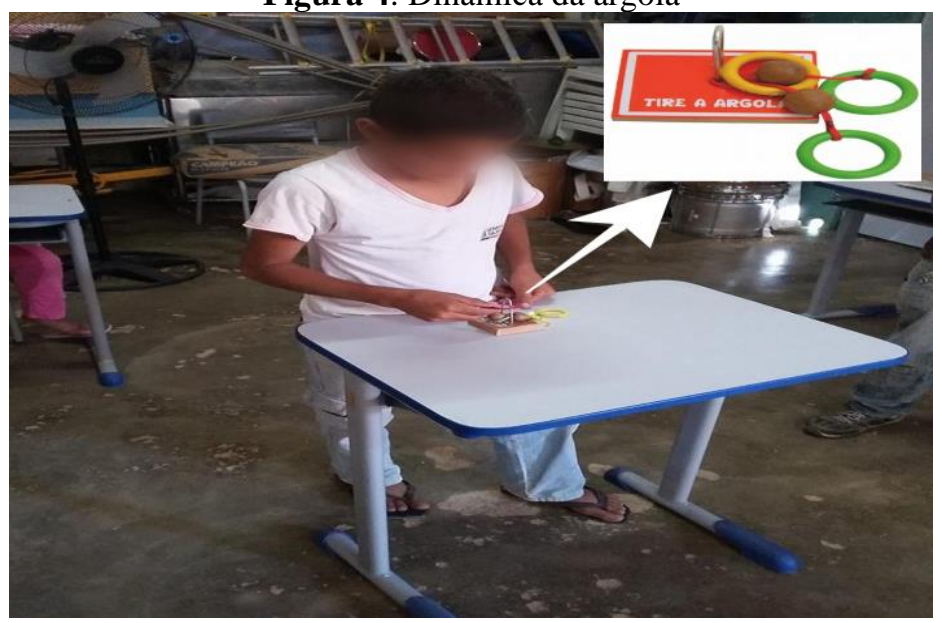

Fonte: Acervo pessoal do pesquisador.

Depois desses momentos de leitura e motivação, passamos, então, para a reflexão acerca do texto, momento primordial na amarração das ideias. Para tanto, criamos um questionário 
sobre o cordel lido. As perguntas que estruturaram o questionário podem ser vistas na imagem abaixo:

Figura 5: Questionário para discussão do cordel A vida de Cancão de fogo e o seu testamento

1) O que vocês entendem quando alguém fala as seguintes expressões linguísticas que são encontradas no cordel, como: Enfadar, quengo, estradeiro, caloteou, enfadado?

2) Qual a importância do Cancão para o desenvolvimento da história? Que papel ele desempenha na trama?

3) Cite algumas situações de esperteza que fez com que o protagonista se livrasse de situações embaraçosas.

4) Como sabemos há na sociedade a história de que somente o homem é mais forte, de que ele é mais esperto. Será que por esses motivos o protagonista da trama é um homem? Não poderia ser uma mulher? E se fosse uma mulher? Como ela seria?

5) Depois de lido o cordel, aponte os motivos de o texto ser intitulado $A$ vida de cancão de fogo e seu testamento.

6) Leia a seguinte estrofe:

$$
\begin{gathered}
\text { Cancão ena um apelido } \\
\text { Que as irmãos lhe puseram; } \\
\text { Pelas travessuras dele } \\
\text { Esse apelido the deram, } \\
\text { Por ele numca querer } \\
\text { Oque as parentes quiseram }
\end{gathered}
$$

Diante disso, vocês poderiam citar algumas travessuras que fizeram com que o protagonista recebesse esse apelido?

7) Percebemos ao longo de toda a narração que Cancão não encontra nenhum amor. Diante disso, qual seria o amor ideal para o protagonista?

8) Para vencermos na vida precisamos da esperteza?

9) Você se considera uma pessoa esperta?

Fonte: Acervo pessoal do pesquisador

Com o término da discussão, passamos para a leitura do segundo cordel "As proezas de João Grilo Neto", de Antônio Lucena. O objetivo foi, a partir de um diálogo entre textos, levar os alunos a estabelecer paralelos entre os protagonistas. Esse diálogo foi iniciado a partir também da exposição de algumas imagens que faziam referências a personagens que eram citados no início desse segundo texto e eram tidos como símbolos de esperteza. Assim, levamos para os alunos imagens de Vicente, o rei dos ladrões; de Mestre Pedro Quengo; de Pedro Malasartes e do próprio João Grilo, que foi o avô de João Grilo Neto.

É válido mencionar que, diferentemente da divisão em blocos situacionais, recurso de leitura a que recorremos quando do trabalho com o primeiro cordel, para a leitura do segundo cordel, valemo-nos da leitura colaborativa entre alunos e professor. Mas, antes, realizamos algumas inferências (GIROTTO; SOUZA, 2010) a partir de perguntas como: Quando eu falo de João Grilo Neto de quem vocês lembram? O que vocês entendem por proezas? O que será que o personagem principal da trama vai aprontar na história? Será que ele é bom ou do mal? $\mathrm{O}$ personagem realiza, em meio à sociedade, coisas boas ou ruins?, entre outros 
questionamentos que procuravam levar os alunos a antecipar, imaginar eventos que poderiam ser ou estar narrados no texto a ser lido.

Dessa maneira, sobre o segundo cordel - As proezas de João Grilo Neto - só foi possível realizar a leitura compartilhada, entre professor e alunos, e promover o momento de reflexão, que teve como objetivo estabelecer comparações entre os personagens citados anteriormente e extrair inferências acerca do personagem João Grilo.

Depois de termos finalizado as leituras e as suas devidas reflexões, pretendíamos solicitar a produção de um texto que seria intitulado de Manual do caboclo esperto. Nesse manual, os alunos teriam que escrever pequenas dicas, em formato de manual de instrução, de como ser um "cabra" esperto em meio aos problemas da vida. Contudo, a produção não ocorreu, devido aos problemas citados na introdução deste texto. Essa produção seria antecedida por dois momentos: o primeiro seria uma aula expositiva sobre como escrever um manual de instrução e o segundo seria uma dinâmica que foi denominada de $O$ saco das adivinhações. Diante da inviabilidade de realização do primeiro momento, visto que o ano letivo já estava às vésperas de ser encerrado, realizamos apenas o segundo momento, uma vez que foi uma maneira que encontramos para finalizar as nossas atividades pedagógicas.

Assim, $O$ saco das adivinhações ${ }^{9}$ se deu da seguinte forma: a turma foi dividida em duas equipes para que elas pudessem percorrer sobre um tabuleiro quadriculado que foi afixado no chão da sala. Cada quadrado foi enumerado, somando, assim, uma numeração de 0 a 30 em todo o tabuleiro. Partindo da estrutura do jogo, criamos um dado que era lançado a cada rodada para que as equipes pudessem avançar no jogo. Cada quadrado teve uma função, seja para os alunos pagar uma prenda, responder a uma pergunta ou até mesmo passar a vez para a equipe concorrente. É válido ressaltar que as adivinhações que deram nome à dinâmica e que motivaram a sua realização em sala de aula versavam sobre esperteza. Dentre as adivinhações presentes no jogo, estavam, por exemplo: “O que é o que é põe na mesa, parte, reparte, mas não se come?". Essa adivinha tem como resposta "Um baralho". Diante disso, além de encerrar a nossa proposta de atividade de uma maneira lúdica, foi possível, a partir dessa dinâmica, trabalhar com a esperteza dos alunos naquele momento de interação entre professor mediador e alunos:

\footnotetext{
${ }^{9}$ A dinâmica recebeu esse nome, pois todas as adivinhas ficaram guardadas em um saco para o qual a cada rodada os alunos eram direcionados a se dirigirem e do qual deveriam retirar uma adivinha.
} 
Figura 6: Apresentação da dinâmica do saco das adivinhações.

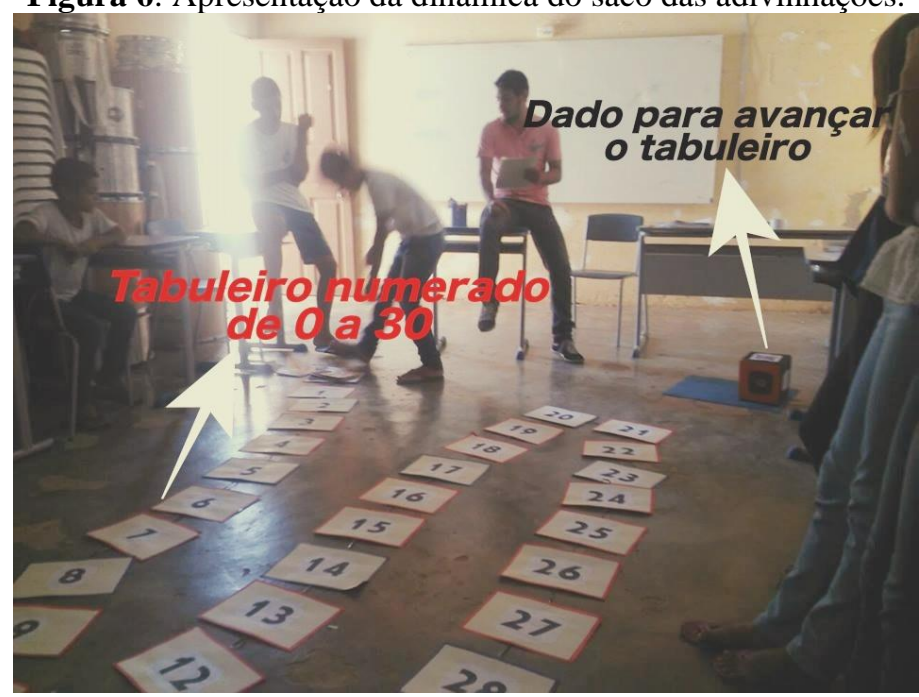

Fonte: Acervo pessoal do pesquisador.

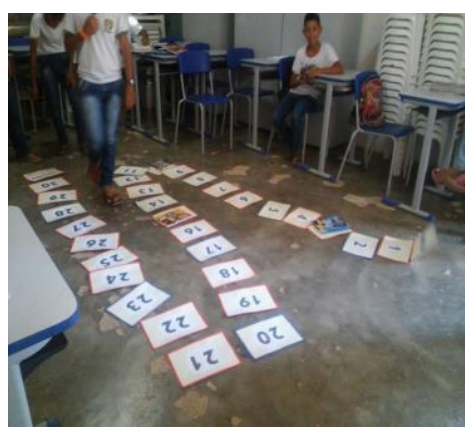

Figuras 7: Realização da dinâmica

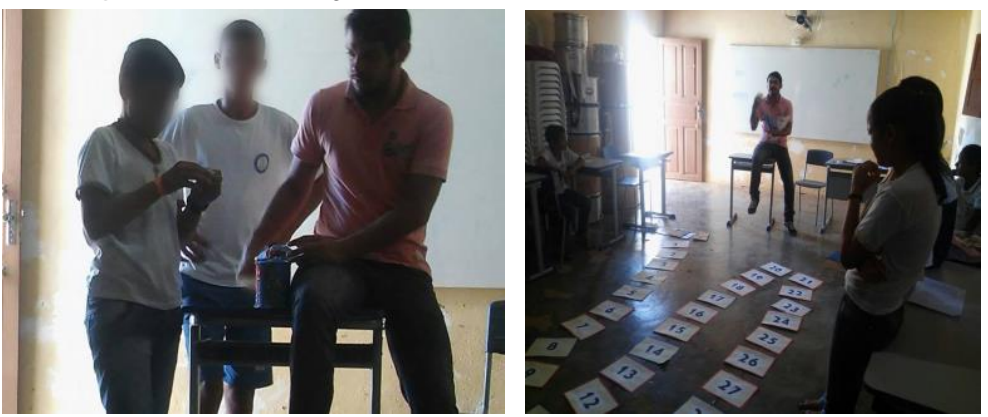

Fonte: Acervo pessoal do pesquisador.

Com a realização dessa dinâmica, encerramos, portanto, a nossa proposta de atividade que, além da iniciação à formação do gosto literário, visou à formação humana de cada um dos alunos que compuseram a turma do $6^{\circ}$ ano da escola em que atuamos no ano de 2016. Acreditamos que o conjunto de atividades descritas anteriormente foi de suma importância não só para os alunos, como também para nós, professores em formação inicial, uma vez que nos deu autonomia para escolher os textos e produzir os materiais pedagógicos necessários para a mediação entre texto, professor e aluno.

\section{Considerações finais}

Ao final da sequência didática aplicada na referida turma, podemos dizer que os resultados obtidos foram satisfatórios, uma vez que, através da leitura efetiva do texto literário e mediante a aproximação entre texto e leitor, pudemos expandir as práticas de leitura dos alunos, como também conseguimos fazer com que o gênero cordel circulasse na instituição em 
que atuamos e fosse conhecido, mais amiúde, pelos alunos, assim como levamos nossos alunos à reflexão crítica acerca do que é ser esperto em nosso país.

Acrescente-se a isso o fato de termos criado condições para uma melhor aproximação entre todos da sala de aula, visto que as atividades realizadas proporcionaram uma maior proximidade entre professor bolsista e os alunos da escola. Esse fato aponta, consequentemente, que a utilização de aulas lúdicas e dinâmicas retira o peso de que o professor é o sujeito detentor de todo o saber. Além disso, o desenvolvimento do conjunto de atividades anteriormente descritas mostra que, mesmo diante das adversidades enfrentadas pela escola e pelo PIBID, é possível realizar um trabalho de grande valia com os alunos da educação básica pública. Acreditamos, pois, em atividades que sejam, realmente, significativas não só para o professor, como também para os alunos.

Por fim, porém não menos importante, reafirmamos a necessidade de um docente que seja muito mais que um transmissor de conhecimentos linguísticos, "a nossa escola precisa de docentes que experimentem formas diversas de ensinar" (SILVA, 2017, s/p), e foi isso que tentamos fazer com o conjunto de atividades propostas: experimentar para, posteriormente, ensinar e formar leitores de literatura.

\section{Referências}

ALBUQUERQUE, Eliana Borges Correia de; LEAL, Telma Ferraz. Literatura e formação de leitores na escola. In: COSSON, Rildo; MACIEL, Francisca; PAIVA, Aparecida (coord.). Literatura: ensino fundamental. Brasília: Ministério da educação, secretaria de educação básica, 2010, p. 89-106.

ALVES, José Hélder Pinheiro. O que ler? Por quê? A literatura e seu ensino. In: DALVI, Maria Amélia; REZENDE, Neide Luzia de; JOVER-FALEIROS, Rita (orgs.). Leitura de Literatura na escola. São Paulo: Parábola, 2014, p.35-49.

BARROS, Leandro Gomes de. A vida do Cancão de fogo e seu testamento. Editora tupiniquin: Fortaleza, 2002.

CANDIDO, Antonio. O direito à literatura. In: CANDIDO, Antonio. Vários escritos. 3. ed. Rev. ampl. São Paulo: Duas cidades, 1995.

CANDIDO, Antonio. A literatura e a formação do homem. In: CANDIDO, Antonio. Textos de intervenção. Seleção, apresentações e notas de Vinicíus Dantas. São Paulo: Ed. 34, duas cidades, 2002.

COSSON, Rildo. Letramento literário: Teoria e prática. São Paulo: Contexto, 2006. 
COSSON, Rildo. O espaço da literatura na sala de aula. In: COSSON, Rildo; MACIEL, Francisca; PAIVA, Aparecida (Orgs). Literatura: ensino fundamental. Brasília: Ministério da educação: Secretaria de educação básica, 2010, p. 55-68.

FERRAREZI JR, Celso; CARVALHO, Robson. De alunos a leitores: o ensino da leitura na educação básica. São Paulo: Parábola, 2017.

GERALDI, João Wanderley. A leitura de texto. In: GERALDI, João Wanderley. Portos de passagem. São Paulo: Martins Fontes, 1997, p. 165-179.

GERALDI, João Wanderley. Unidades básicas do ensino de português. In: GERALDI, João Wanderley. O texto na sala de aula. São Paulo: Ática, 1997, p. 59-79.

GIROTTO, Cyntia Graziella Guizelim Simões; SOUZA, Renata Junqueira. Estratégias de leitura: para ensinar alunos a compreender o que leem. In: SOUZA, Renata Junqueira de. Ler e compreender: estratégias de leitura. Campinas, SP: Mercado de Letras, 2010. p. 45-151.

LUCENA, Antônio. As proezas de João Grilo Neto. Cordelaria Poeta Manoel Monteiro: Campina Grande, sem data.

MARTINS, Thaísa Rochelle Pereira. Entre inferências e conexões: uma sugestão de abordagem com o livro até as princesas soltam pum, de Ilan Brenman. In: SOUZA, Renata Junqueira de; PINHEIRO, Hélder. Literatura infantil e formação de leitores: estratégias de leitura. Campina Grande: UFCG, 2015, p. 55-71.

PINHEIRO, Hélder. Poesia na sala de aula. João Pessoa: Ideia, 2002.

SILVA, Marcelo Medeiros da. Uma estranha na sala de aula: interculturalidade, letramento literário e ensino. Estudos de Literatura Brasileira Contemporânea, Brasília, n. 57, e575, p. 1$13,2019$.

SILVA, Marcelo Medeiros da. Literatura, poesia e ensino: considerações a partir da formação de professores. Revista Práticas de Linguagem. v.7, p.112 - 129, 2017.

SILVA, Marcelo Medeiros da. Falando de leitura, poesia e amor com alunos egressos da Educação de Jovens e Adultos: um estudo de caso. Dissertação de Mestrado. Campina Grande: Universidade Federal de Campina Grande, 2006. 